\title{
Students' perspective on higher educators: interpersonal relationship matters
}

\author{
Ladan Ghazi Saidi ${ }^{1}$ (D) $\cdot$ Phu Vu ${ }^{2}$
}

Received: 7 February 2021 / Accepted: 9 June 2021 / Published online: 6 July 2021

(c) The Author(s), under exclusive licence to Springer Nature Switzerland AG 2021

\begin{abstract}
Students' perspective on the higher educators' performance matters because the ultimate goal of teaching is education quality and students' satisfaction. Student evaluations are important to university professors to improve their teaching quality and in many cases, secure their promotion and tenureship. Excellent teaching does not have a universal definition, and students often have different perspectives on effective and excellent teaching. In this study, we examined the factors contributing to excellent teaching as rated by students on the website ratemyprofessors.com, a popular website among students to rate their educators voluntarily. The information from this website can be valuable, despite all the critics it has received, given that students provide feedback on a volunteer basis to help their peers with selecting the best class. The website provides a forum for opinions that are not influenced by fear of possible consequences, such as a low grade or tension with faculty. Our study results show that the five top characteristics that are important to students include being caring, respectful, inspirational, as well as giving good feedback, and delivering "amazing" lectures. Further data analysis shows that subject content, in terms of manageable workload, reasonable content difficulty, and grading, can influence students' ratings. The findings indicate that students value interpersonal relationships and cherish individualized feedback and receiving personal support.
\end{abstract}

Keywords Student evaluation · Professor · Higher education · Academic · Interpersonal relationship $\cdot$ Content $\cdot$ Subject difficulty

Ladan Ghazi Saidi

ghazisaidil2@unk.edu

1 Department of Communication Disorders, College of Education, University of Nebraska at Kearney (UNK), 1615 West 24th St., Kearney, NE 68847, USA

2 Department of Teacher Education, College of Education, University of Nebraska at Kearney, Kearney, NE, USA 


\section{Introduction}

Quality education at higher institutions is essential, given their role in creating and transfer of knowledge in economics, governance, and social management of daily lives of people globally (Rakhimov et al. 2021; Ramsden 2003; Cheng and Tam 1997). Quality of education is often intertwined with quality of teaching. Teaching is a complex, intellectually and socially demanding task that requires skills (Atkins and Brown 2002). Skills are different from inherited talents in that they can be acquired and improved. To measure (and ultimately improve) the quality of teaching, and therefore education, many institutions use students' evaluation. Students are considered the main stakeholders or consumers of the education institutions (Degtjarjova et al. 2018). Therefore, most universities use students' evaluation to provide feedback to professors about the effectiveness of their teaching, and therefore increase the quality of teaching/learning dynamic (Ory 2000; Remedios and Lieberman 2008). Constructive criticism with good intentions can help educators improve teaching to high standards of teaching, improve their teaching techniques, effectiveness, and quality of education. However, there is overwhelming evidence that students' evaluations are often biased, unfair and based on subjective opinion, rather than reflecting the objective criteria that are classically known for quality education and effective teaching (Bumjaid and Malik 2019; Rainey et al. 2019; May and Tenzek 2018; Clayson 2014; Narang 2012; Wolfe and Powell 2009; Felton et al. 2004). This is particularly important, given that results of student evaluations can impact educators' reputation and even in some institutions, may cost them losing their career, if student evaluations are not excellent.

Some education systems today world-wide, including higher education institutes in the US, use students' evaluation as a way to measure the educators' performance as a teacher (Murray et al. 2020; Freeman and Dobbins 2013; Kember and Leung 2008), a determining factor in promotion and tenureship decisions. Therefore, the impact of students rating educators has evolved into a powerful tool in determining the faith of untenured professors (Freeman and Dobbins 2013). Given that students' evaluations have been well established in most educational institution systems, and it is less likely that it would change anytime soon, it is crucial to have a deep and accurate understanding of what student evaluations reflect. Further, for universities as well as for educators, it is crucial to understand the variables that play an essential role in students' evaluations. Moreover, it is important to discuss the roots of such variables from the students' viewpoints and their differences from the educators' viewpoints. In this regard, educators and students typically have different perspectives, definitions, and criteria for what makes teaching effective and how a professor is considered excellent. Therefore, we should define the characteristics of an excellent professor. There may be no universal understanding or definition of what makes a professor a good one. Typically, characteristics are defined based on the purpose. In higher education, the purpose is typically practical (Wood and Su 2017; Skelton 2005; Ory 2000). Practicality includes an objective (to the extent possible), measurable outcomes such as performance of the students on standardized tests or the trend of grades in a given class (Jackson 2018; Andrews et al. 1996; Feldman 1976). 
Bain in his well-known book, What the Best College Professors Do, identifies a set of core characteristics of exemplary college educators (Bain 2004). Bain generated his recommendations by interviewing, assessing, and observing over 60 outstanding professors across many disciplines and kinds of higher education institutions. These professors were identified through the awards they had received and their reputations for high-quality teaching. According to Bain (2004), excellent professors produce "important educational results" (p. 5), such as high achievement on standardized and professional tests and satisfied, inspired students. In this definition, Bain (2004) puts objective, measurable outcomes such as standardized tests and subjective psychological factors such as satisfaction and inspiration in one sentence. Nevertheless, he is ultimately defining an excellent professor, someone who achieves high educational results. Educational results, is in fact, what most faculty from a broad spectrum of disciplines agree on. Faculty from Pharmacy (Ford 2016), to psychology (Soomere et al. 2018), and military (Keeley et al. 2006) agree that the most important quality of a professor is stimulating critical thinking and creativity, being effective in communication and providing opportunities for discussion and being knowledgeable about the content and therefore confident. Other exciting factors have listed as holding interesting classes, being enthusiastic about teaching and the topic, and providing constructive feedback while being respectful, approachable, and personable (Wood and Su 2017). These qualities can be categorized as knowledge of the content and delivering the content and interpersonal relationship with students.

While most professors and universities emphasize educational results, students have a different perspective. For students, excellent teaching is about assessment (grading) and workload rather than long-term development. It is gender-biased and depends on the subject the professor teaches (Alhija 2017; Andrews et al. 1996). This means for the student immediate reward, such as a better grade or doing less homework, seems to be more critical than the postponed gratification (such as developing critical thinking or a skill). While professors may not necessarily agree with students' view points or the weight they put on different aspects of their teaching, it is, important for the professors to understand the variables that shape the students' perception and definition of excellent teaching. It is crucial to identify and discuss the roots of such variables from the students' viewpoints and their differences from the professors' viewpoints. Thus, the Research Question in this study is the following: what are the characteristics that shape the students' perception and definition of excellent teaching, as rated on MyProfessors.com.

\section{Materials and methods}

The primary purpose of this study was to identify the characteristics that shape the students' perception and definition of an excellent educator, as rated on RateMyProfessors.com. We chose to use ratings provided by students on a website named RateMyProfessors.com to assure that external pressure (e.g., grades, fear, etc.) does not influence the responses in our sample. Further, open websites have become a part of performance evaluation criteria at universities, and hence would 
be a great resource for research (Rosen 2018; Steffes and Burgee 2009; BleskeRechek and Fritsch 2011; Clayson 2014). We chose an open access web-based forum given that it provides a safe and self-motivated environment, where students favor to provide ratings and opinion about their educators (Davison and Price 2009). In addition, an international open access web-based rating site with millions of users from thousands of universities allows avoiding sampling bias and therefore better generalization and higher validity. According to the website of RateMyProfessors.com, it is the largest online destination for professor ratings with more than 19 million ratings. Each month, more than four million college students each month use the website to rate their educators voluntarily. On this site, 1.7 million professors and over 7500 schools have been rated. RateMyProfessor.com has been used in credible previous studies focusing on different research questions at different times, supporting the datasets' validity and reliability (e.g., Rosen 2018; Felton et al. 2004; Kowai-Bell et al. 2011; Lewandowski et al. 2012; Riniolo et al. 2006).

We examined what factors contributed to the perfect ratings (five- star ratings) professors received on the website ratemyprofessors.com. When a user visits the website, they can search for a specific name of a professor at a specific institution and use a five-point scale (1-5) to rate the professor, and pick a level of difficulty of the subject matter on a five-point scale (1-5). The user can also select up to three tags that describe the professor from a list of 20 . In addition, they have the option to write open comments on that specific professor. However, we did not include this information in our analyses to avoid subjective bias and higher validity.

We used the disproportionate stratified sampling research technique to identify four-year higher education institutions eligible for inclusion in our study. We did not know the exact sample size that would be in each stratum. According to Kalton (1983), a stratified sampling research technique has more advantages over other sampling techniques because stratifying helps reduce sampling error and ensure a higher level of representation. The first step of our data collection and analysis was identifying and verifying colleges' eligibility entered into the data pool. To do so, we used the Fobres' list of 650 universities rated as the best universities in the country (2019). Fobres' university rankings demonstrate based on six general categories: Alumni Salary (20\%), Student Satisfaction (20\%), Debt (20\%), American Leaders (15\%), On-Time Graduation Rate (12.5\%), and Academic Success (12.5\%). Then, we created six strata to ensure that the actual sample representation included in the data pool, which were as follows: flagship public/state universities, regional public/ state universities, selective/ivy league universities, small liberal arts colleges/ universities, not-for-profit online universities, and for-profit online universities. We collected the data between August 2019 and January 2020.

We were also aware of concerns about the external validity of the ratings on the ratemyprofessor.com including the absence of psychometric information about the RateMyProfessors-defined categories, rating bias, and information about the representativeness of the students who used the website (Gregory 2011; Otto et al. 2008a, b). We will discuss the first two concerns in the limitation (p. 16). To minimize the possible limits of the external validity of the data, due to the latter concern, we selected only professors with perfect ratings who received at least ten ratings. 
Within the scope of this study of investigating what factors contributed to the perfect rating professors, we examined the level of course difficulty via a five-point scale (1-5), and students' descriptions of the professors with the provided descriptive tags. The inclusion criteria consisted of (a) perfect rating (5 points), (b) working for an institution on the Fobres' 650 best universities 2019, randomly selected from each stratum, and (c) having at least ten ratings. The website invites the raters to select up to three "tags" as for each professor. The website ratemyprofessors.com provides 20 descriptive tags for users. Two coders calculated the tags for every professor who was rated perfect (five stars) by at least ten students. The quantitative analyses included the descriptive analysis of the top five descriptive tags used for all professors with perfect ratings. In addition, we examined the level of course difficulty via a five-point scale (1-5) associated with professors with perfect ratings. According to the website ratemyprofessors. com, the five-point scale interpreted as 1 for "show up and pass", 2 for "easy A," 3 for "the usual," 4 for "make you work for it," and 5 for "the hardest thing I've ever done.

\section{Results}

The data analyses showed that all the professors with perfect rating taught courses that were considered as easier than usual. Thus, the mean score of the level of course difficulty associated with professors who had perfect ratings is 2.42 out of 5.00. This puts them on "easy" to "usual".

Table 1, below, shows the data that present the results of the descriptive analysis.

The second factor we examined was how students described the professors with perfect ratings. Table 2 below summarizes the frequency of descriptive tags used to describe professors who had perfect ratings.

Data on Table 2 and Fig. 1 indicated that the top five descriptive tags professors with perfect ratings got were "caring," "respected," "inspirational," "give good feedbacks", and "amazing lectures".

\section{Discussion}

In summary, our results show that professors, who rated as perfect, had two main characteristics in common: their subject matter was perceived as "easy" to "usual," and they were described as caring, respectful, inspirational, and helpful (provide useful feedback and amazing lectures). In brief, students value interpersonal relationships both at social and educational levels.

To students, an excellent professor has the art of teaching. The art of teaching is fundamentally rooted in student-professor interaction (Simpson and Galbo 1986),

Table 1 Descriptive analysis of level of course difficulty

\begin{tabular}{lllll}
\hline Total & Mean & Mode & Median & Range \\
\hline 417 & $2.42 / 5.00$ & $2.40 / 5.00$ & $2.40 / 5.00$ & 3.00 \\
\hline
\end{tabular}


Table 2 Descriptive tags describing professors with perfect ratings

\begin{tabular}{|c|c|c|}
\hline No. & Descriptive tags & Total \\
\hline 1 & Caring & 2248 \\
\hline 2 & Respected & 2213 \\
\hline 3 & Inspirational & 999 \\
\hline 4 & Give good feedbacks & 882 \\
\hline 5 & Amazing lectures & 872 \\
\hline 6 & Hilarious & 786 \\
\hline 7 & Accessible outside classrooms & 489 \\
\hline 8 & Participation matters & 336 \\
\hline 9 & Clear grading criteria & 294 \\
\hline 10 & Skip class? You won't pass & 268 \\
\hline 11 & Extra credit & 205 \\
\hline 12 & Lots of home-work & 152 \\
\hline 13 & Get ready to read & 142 \\
\hline 14 & Group projects & 81 \\
\hline 15 & Tough grader & 56 \\
\hline 16 & Graded by few things & 54 \\
\hline 17 & Lecture heavy & 53 \\
\hline 18 & So many papers & 32 \\
\hline 19 & Beware of pop quizzes & 29 \\
\hline 20 & Test heavy & 26 \\
\hline
\end{tabular}

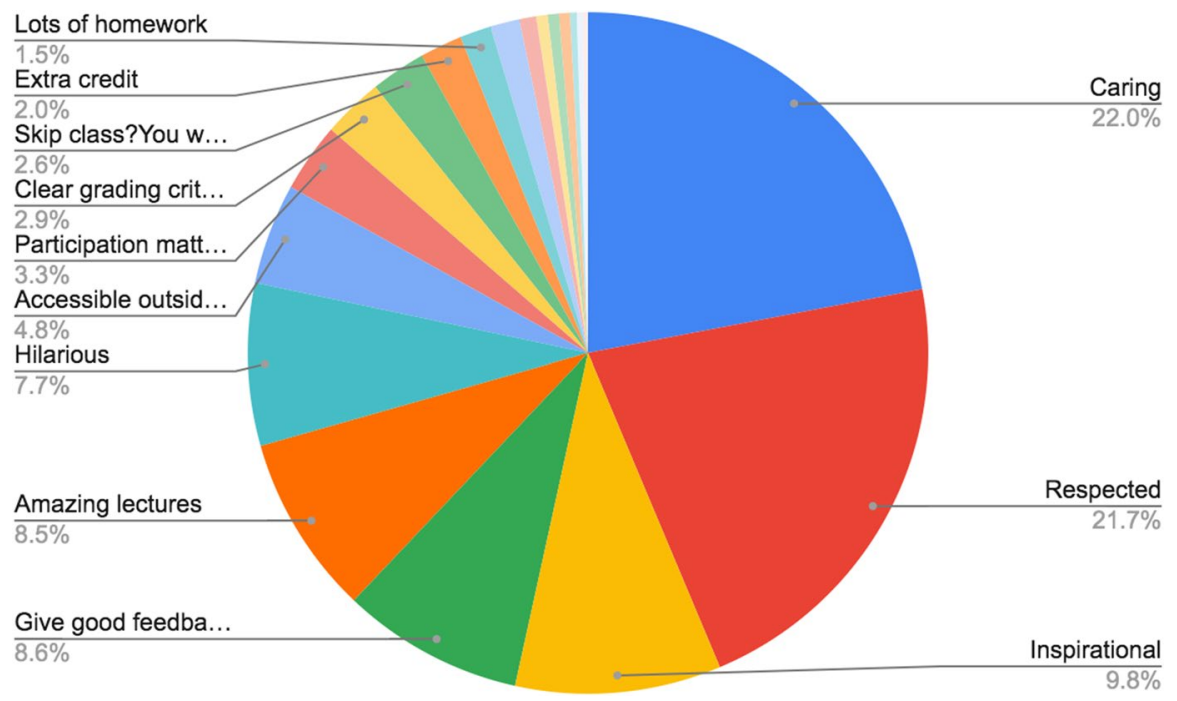

Fig. 1 Percentage of students using descriptive tags describing professors with perfect ratings 
and effective communication (Smart et al. 2003). Student-educator interaction and communication have been studied in depth in a recent study (Asikainen et al. 2018). In this study, both students and educators were asked to describe the student-educator relationship using open-ended questions. The results showed that responses could divide into five categories, from high-quality relationships to low-quality relationships. The definition students provided for high-quality relationships included keywords that were frequently used by most students. These keywords included "friendly," "approachable," and "nice," also, students used different wordings that referred to "responsiveness and respectful" (Asikainen et al. 2018).

This is consistent with the results of this study and the results of our previous finding with a local sample of our own classes (Ghazi-Saidi et al. 2020). Based on our findings, we argue that students' evaluations are typically subjective rather than objective (i.e., with measurable outcomes). In addition, the adjectives students have used to describe excellent professors (e.g., caring, respectful, inspirational) reflect that students' evaluations are based on how they feel in the class and toward the educator. Feelings may develop as a result of educator-student interpersonal relationships, due to the difficulty (Felton et al 2004, 2008), excitement or other content related matters of the subject the educator teaches, or may be rooted in general implicit biases such as gender bias, ethnicity bias, etc. (Rainey et al. 2019; May and Tenzek 2018; Wolfe and Powell 2009; Felton et al. 2004). For example, they may feel uncomfortable in class, or conversely, they may feel excited about the subject matter, and this negative or positive feeling can impact the educator's evaluation. To this point, an inspirational educator can evoke hope, motivation and other positive feelings, and thus result in an excellent rating.

This interpretation is partly in line with the arguments made by Bain (2004). Bain argues that excellent professors change the way students "think, act or feel" (p. 7). One problem with such a definition is that it mixes measurability and performance with feelings (Wood, and Su 2017). Feeling and thinking or acting may be different, rooting from different sources. Further, thinking and acting may be measurable by objective outcomes, typically as what we referred to earlier as educational results. More importantly, such outcomes can be predictable and are typically universal (e.g., scoring $100 \%$ on a national exam or occupying a well-paid position). In contrast, feelings are subjective and individualized and, therefore, unpredictable. This is why there is an essential need to understand what underlying factors students' evaluation rating root from, to address students' needs, as well as holding less biased and fairer tenureship criteria in place.

Here, we use an example to clarify such a need. Some educators may define excellent teaching as the ability to transfer the facts (knowledge). They may consider themselves knowledgeable and work hard on the course content but to their surprise, at the end of the semester, students' evaluation may not be positive. They may find students' evaluations unfair, biased, and unrepresentative of them. On the students' side, however, perception of teaching excellency may be different. Students may not appreciate a knowledgeable educator when they expect a profound transformative experience that inspires them but do not receive it.

Students define excellency in teaching as holding strong interpersonal relationships that are positive, supportive, respectful, and inspirational. Interpersonal 
relationships are essential in the context of teaching, regardless of the educator's knowledge. Knowledge is necessary, but it is by no means sufficient. From a psychological viewpoint, knowledge level can be indirectly related to interpersonal relationships. Standing in front of a crowd and claiming to have knowledge about a subject matter is demanding, intimidating, and stressful. It requires self-confidence, confidence in being knowledgeable about the subject matter, and confidence in the ability to transfer the knowledge. Therefore, the educator's knowledge and subject mastery would indirectly support their comfort level in teaching the content, which can ease up building positive student-educator relationships. Moreover, knowledge helps with effective and clear communication. Only when a concept is deeply understood, can it be transferred to others clearly and effectively. However, the art of teaching includes creative ways to simplify complex and complicated subjects into easy to understand concepts, using examples, similes, videos, images, and other supporting materials.

Another characteristic that is valued by students is being helpful. This has been defined as "giving good feedback" and "amazing lectures." Students cherish individualized feedback and lectures that are meaningful and include personally relatable examples. Also, students get motivated to learn and become active if they feel respected and cared for. This shows that students' perspectives and perceptions of an excellent professor do not precisely match what educators and institutions define as "excellent." Educators and institutions value educational results (e.g., critical thinking, developing skills, etc.) and have a relatively long-term outcome vision in mind (e.g., successful careers), whereas students seem to prefer immediate reward to longterm gratification (Bembenutty 2009), and prioritize high-quality interpersonal relationships to content matter.

Other factors students find important include manageable workload, perception of subject difficulty, and grading. In other words, to students, subject content matters only to the extent that affects their immediate experiences. Students expect the difficulty level of the subject to be reasonable, have a manageable workload, and ultimately want a clear and straightforward grading system that ends with high and fair grades. Designing a system that meets students' expectation in this regard, takes knowledge of the content, knowledge, and vision of what is required, what is relevant, and what is optional for students to know, to determine a workload for students that is at the right difficulty level and manageable, as well as determining a grading system that is both easy to understand for students and meaningful in terms of assessing if students have learned required content. Mastery of the content will allow designing a course work and grading system that considers what students prefer including immediate reward (e.g., good grades, a manageable workload, and easy access to their professor). At the same time, counterintuitively, students look for a mentor who inspires them to achieve their goals and support them through their journey. To some educators, students seem oblivious to the fact that the easy and generous practices of teaching they value are highly unlikely to result in life-changing success they hope to achieve. Successful outcomes and long-term educational results require developing skills and critical thinking. For instance, Bain (2004) argues excellent professors produce "important educational results" (p. 5), such as high achievement on standardized and professional tests and satisfied, inspired 
students. In these educators' classes, understanding is more important than remembering, arguments and evidence are more important than facts and figures. In Bain's view, excellent teaching has little to do with implementing a set of teaching tips or best practices. Instead, excellent teaching focuses on unusual and remarkable results like sustained and deep understanding, a fundamental change in the student's world view and mental models, a desire to learn more, and the effective communication of the educators' attitudes toward their profession, discipline, and students. It is worth noting that unlike our study, in Bain's study, excellent professors were identified through being recognized by receiving awards and their reputations for high-quality teaching.

In contrast, in our study, only students determined the excellency of the professor. Nevertheless, this difference in perspective is not necessarily in odds with each other. Bain essentially argues that learning effects are more important than storing information. From a cognitive viewpoint, individuals can store much information that may never get retrieved or used, but only when behavioral changes happen, do we consider learning to have occurred. Learning requires active cognitive effort and information consolidation (Karpicke 2012). Learning consolidation results in behavioral changes such as mastery in a skill (Berkman 2018; Antony et al. 2017; Bouton 2000), or changes in perspectives, attitudes, and future plans as well as the motivation to achieve goals. This is where the art of teaching merges teaching hardcore objective facts on the one hand and subjective psychological variables such as inspiration and satisfaction on the other. This is interestingly in line with what Bain (2004) concludes. The students of the best educators learn the content, and learn to love learning, which in turn provides a sustained and significant impact on the students' lives. In fact, what Bain puts forward is "inspiration," which is in line with our results. Not understanding this dynamic may be why many educators, especially those in STEM or those who are less experienced in teaching, may feel confused about interpreting their students' evaluation responses.

\section{Conclusion}

In this study, we examined the factors contributing to excellent teaching as rated by students on the website ratemyprofessors.com, a website with more than 19 million ratings. The results of our study show that the five top characteristics that are important to students include being caring, respectful, inspirational, and giving good feedback and amazing lectures. Further data analysis shows that subject content matters in terms of manageable workload, reasonable content difficulty, and grading. This shows that students value interpersonal relationships and expect to receive helpful support. Forums where students can voice their concerns, wants and needs are necessary to provide educators with a better understanding of students' perspectives. Teaching is an interactive task involving both educators and students. Given that students are the main consumers or stakeholders of higher education institutions, their satisfaction and therefore views are important. Our results reflect that students' perspective may not necessarily match the research-based criteria for quality education, 
such as educator's expertise and knowledge, objective students' outcomes and pedagogical standards.

\section{Limitation of this study and suggestions for future studies}

In this study, we used an open and publically available online website to collect the data. Although such big databases are statistically powerful and provide a reliable sample size, given that there is no control over sample collection, given that anyone can go on this website and rate a professor, the data can be unreliable. Further, in a circumstance, such a publicly open online, where students evaluate a professor voluntarily, typically students are either extremely happy or extremely unhappy with their experience with their educator. This means that the data miss the average student by large. A longitudinal study may reveal information on how consistent rating are over time. Further, the site has received some criticism, on the categories including not providing a definition for some terms such as "helpfulness" and "easy or difficult", and neglecting important teaching aspects such as preparedness and rigor. Other criticism refer to students' comments that are biased and based on characteristics that are not relevant to teaching such as physical appearance. While we acknowledge these criticisms, we argue that such criticism on the part of educators can reflect students' and educators' different perspectives. Moreover, despite these shortcomings, the results are is in line with most class evaluations in any given course, especially if evaluations are optional (Rosen 2018; Bleske-Rechek and Michels 2010). In future studies, it would be interesting to compare samples that include only required student evaluations and voluntary student evaluations.

Another interesting comparison would be samples including only face-to-face courses and only online courses. Although online courses are becoming very popular due to many advantages from financial considerations to time and place flexibility, they entail many differences from face-to-face classes. Such differences include cognitive and affective (Coppola et al. 2002), pedagogical, technical, and social (Berge 1999), as well as managerial issues (Coppola et al. 2002; Berge 1999). Given the lack of direct or face-to-face student-educator interaction in an online environment, it would be interesting to study how interpersonal relationships fold out. A relatively recent study has shown that interpersonal relationships in online environments are similar and correlated to face-to-face courses ( $\mathrm{Li}$ et al. 2018). Interpersonal relationships and strong communication were identified as important contributing factors for a successful face-to-face to online course transition during COVID-19 university shutdown (Ghazi-Saidi et al. 2020). Many questions remain unanswered, however. Examples follow. How do interpersonal relationship dynamics change in a virtual environment? How can educators show "care" and "passion" online? Are the needs and wants of students the same or different?

Another interesting issue worth further studying, is the relationship between interpersonal relationships and biases that impact students' evaluations. If students find interpersonal relationships as the most important factor in teaching excellency, it becomes clear why personal and demographic characteristics of an educator can influence student evaluation rating (Basow 1995; Bavishi et al. 2010; Basow et al. 
2013; Joye and Wilson 2015; Boring 2017). Demographic factors such as gender, race or ethnicity, and appearance have been reported repeatedly in the literature to affect student evaluations (Rainey et al. 2019; May and Tenzek 2018; Wolfe and Powell 2009; Felton et al. 2004; Basow 1995; Bavishi et al. 2010; Basow et al. 2013; Joye and Wilson 2015; Boring 2017). This implicit (or in cases explicit) bias can influence interpersonal relationships. Interpersonal relationships are inevitably mutual. If there is a biased negative impression of an educator due to their demographic features, a positive relationship may never form. The solution may be in education and awareness both on university administrations' and students' sides. Better understanding of the impact of implicit and explicit biases on interpersonal relationships can lead to acceptance of everyone and commitment to internalizing and embracing diversity, enhancing interpersonal relationships regardless of demographic factors and indirectly increasing teaching/learning quality. This would be worthwhile to compare a cohort that has received an awareness or deep learning training to one that has not.

Funding No funds, grants, or other support was received.

Data availability The datasets generated during and/or analyzed during the current study are available from the corresponding author on reasonable request.

\section{Declarations}

Conflict of interest Authors have no financial or personal relationship with a third party whose interests could be positively or negatively influenced by the article's content.

Ethical approval Authors' IRB approval.

\section{References}

Alhija FNA (2017) Teaching in higher education: good teaching through students' lens. Stud Educ Eval 54:4-12

Andrews J, Garriso DR, Magnusson K (1996) The teaching and learning transaction in higher education: a study of excellent professors and their students. Teach High Educ 1(1):81-103

Antony JW, Ferreira CS, Norman KA, Wimber M (2017) Retrieval as a fast route to memory consolidation. Trends Cogn Sci 21(8):573-576

Asikainen H, Blomster J, Virtanen V (2018) From functioning communality to hostile behavior: students' and professors' experiences of the professor-student relationship in the academic community. J Furth High Educ 42(5):633-648

Bain K (2004) What the best college professors do. Harvard University Press, Cambridge, MA

Bembenutty H (2009) Teaching effectiveness, course evaluation, and academic performance: the role of academic delay of gratification. J Adv Acad 20(2):326-355

Berge ZL (1999) Interaction in post-secondary, Web-based learning, and teaching. Educ Technol 39(1):5-11

Berkman ET (2018) The neuroscience of goals and behavior change. Consult Psychol J Pract Res 70(1):28

Bleske-Rechek A, Fritsch A (2011) Student Consensus on RateMyProfessors.com. Pract Assess Res Eval 16(18):1-12 
Bouton ME (2000) A learning theory perspective on lapse, relapse, and the maintenance of behavior change. Health Psychol 19(1S):57

Bumjaid SE, Malik HAM (2019) The effect of implementing of six sigma approach in improving the quality of higher education institutions in Bahrain. Int J Eng Manage Res 9:134-140

Cheng YC, Tam WM (1997) Multi-models of quality in education. Qual Assurance Educ 5:22-31

Clayson DE (2014) What does Ratemyprofessors.com actually rate? Assess Eval High Educ 39(6):678-698

Davison E, Price J (2009) How do we rate? An evaluation of online student evaluations. Assess Eval High Educ 34(1):51-65

Degtjarjova I, Lapina I, Freidenfelds D (2018) Student as stakeholder: "voice of customer" in higher education quality development

Feldman KA (1976) Grades and college students' evaluations of their courses and professors. Res High Educ 4(1):69-111

Felton J, Mitchell J, Stinson M (2004) Web-based student evaluations of professors: the relations between perceived quality, easiness and sexiness. Assess Eval High Educ 29(1):91-108

Felton J, Koper PT, Mitchell J, Stinson M (2008) Attractiveness, easiness and other issues: student evaluations of professors on Ratemyprofessors.com. Assess Eval High Educ 33(1):45-61

Ford C (2016) Identifying effective teaching behaviors of pharmacy faculty master professors

Freeman R, Dobbins K (2013) Are we serious about enhancing courses? Using the principles of assessment for learning to enhance course evaluation. Assess Eval High Educ 38(2):142-151

Ghazi-Saidi L, Criffield A, Kracl CL, McKelvey M, Obasi SN, Vu P (2020) Moving from face-to-face to remote instruction in a higher education institution during a pandemic: multiple case studies. Int $\mathrm{J}$ Technol Educ Sci 4(4):370-383

Gregory KM (2011) How undergraduates perceive their professors: A corpus analysis of Rate My Professor. J Educ Technol Syst 40(2):169-193

Jackson CK (2018) What do test scores miss? The importance of professor effects on non-test score outcomes. J Polit Econ 126(5):2072-2107

Karpicke JD (2012) Retrieval-based learning: active retrieval promotes meaningful learning. Curr Dir Psychol Sci 21(3):157-163

Keeley J, Smith D, Buskist W (2006) The Professor Behaviors Checklist: factor analysis of its utility for evaluating teaching. Teach Psychol 33(2):84-91

Kember D, Leung DY (2008) Establishing the validity and reliability of course evaluation questionnaires. Assess Eval High Educ 33(4):341-353

Kowai-Bell N, Guadagno RE, Little T, Preiss N, Hensley R (2011) Rate my expectations: how online evaluations of professors impact students' perceived control. Comput Hum Behav 27(5):1862-1867

Lewandowski GW, Higgins E, Nardone NN (2012) Just a harmless website?: An experimental examination of RateMyProfessors.com's effect on student evaluations. Assess Eval High Educ 37(8):987-1002

May A, Tenzek KE (2018) Bullying in the academy: understanding the student bully and the targeted 'stupid, fat, mother fucker'professor. Teach High Educ 23(3):275-290

Murray D, Boothby C, Zhao H, Minik V, Bérubé N, Larivière V, Sugimoto CR (2020) Exploring the personal and professional factors associated with student evaluations of tenure-track faculty. PLoS ONE 15(6):e0233515

Narang R (2012) How do management students perceive the quality of education in public institutions? Qual Assurance Educ. 20:357-371

Ory JC (2000) Teaching evaluation: past, present, and future. New Dir Teach Learn 83:13-18

Otto J, Sanford DA, Ross DN (2008a) Does Ratemyprofessor.com really rate my professor? Assess Eval High Educ 33(4):355-368

Otto J, Sanford DA Jr, Ross DN (2008) Does ratemyprofessor.com really rate my professor? Assess Eva High Educ 33(4):355-368

Rainey K, Dancy M, Mickelson R, Stearns E, Moller S (2019) A descriptive study of race and gender differences in how instructional style and perceived professor care influence decisions to major in STEM. Int J STEM Educ 6(1):1-13

Rakhimov OD, Rakhimova DO, Dustkabilovich-Professor RO (2021) Educational quality in the era of globalization. Проблемы Науки 1:60

Remedios R, Lieberman DA (2008) I liked your course because you taught me well: the influence of grades, workload, expectations, and goals on students' evaluations of teaching. Br Edu Res J 34(1):91-115

\section{SN Social Sciences}


Riniolo T, Johnson K, Sherman T, Misso J (2006) Hot or not: do professors perceived as physically attractive receive higher student evaluations? J Gen Psychol 133(1):19-35

Rosen AS (2018) Correlations, trends and potential biases among publicly accessible web-based student evaluations of teaching: a large-scale study of RateMyProfessors.com data. Assess Eval High Educ 43(1):31-44

Simpson RJ, Galbo JJ (1986) Interaction and learning: theorizing on the art of teaching. Interchange. $17: 37-51$

Skelton A (2005) Understanding teaching excellence in higher education: towards a critical approach. Routledge, London and New York

Smart DT, Kelley CA, Conant JS (2003) Mastering the art of teaching: pursuing excellence in a new millennium. J Mark Educ 25(1):71-78

Soomere T, Lepp L, Groccia J, Mansour EAI (2018) Characteristics and behaviors of excellent teaching: perceptions of military educators. In INTED2018 Conference, pp 6736-6744

Steffes EM, Burgee LE (2009) Social ties and online word of mouth. Internet Res 19(1):42-59

Wolfe J, Powell E (2009) Biases in interpersonal communication: How engineering students perceive gender typical speech acts in teamwork. J Eng Educ 98(1):5-16

Wood M, Su F (2017) What makes an excellent lecturer? Academics' perspectives on the discourse of 'teaching excellence' in higher education. Teach High Educ 22(4):451-466 